\title{
La influencia de los aspectos socioculturales y lingüísticos en los niveles de literacidad: el caso de alumnos de la Facultad de Idiomas, Universidad Veracruzana'
}

The Influence of Sociocultural and Linguistic Aspects in the Literacy levels: The student case of the Language Department, University of Veracruz

\author{
JOSÉ ÁNGEL ESCARPETA SÁNCHEZ \\ Universidad Veracruzana \\ México \\ joseangelescarpeta@yahoo.com
}

(Recibido: 28-OI-2OI8; aceptado: o6-II-2OI8)

Resumen. En este trabajo planteamos como problema principal el que muchos alumnos recién ingresados a la Facultad de Idiomas, Universidad Veracruzana, presentan niveles bajos en literacidad, en comparación con otros que son competentes en esta. No consideramos como respuesta a estas interrogantes que los alumnos sean incapaces intelectualmente, o sin interés. Nuestra hipótesis es distinta. Existen grandes diferencias en los niveles de lectura y escritura de los alumnos porque inciden en estos los aspectos socioculturales y lingüísticos, los cuales tienen mucha influencia para la formación competente o no de lectores y escritores. Hemos estructurado este trabajo de la siguiente manera: primero definimos y explicamos qué es la teoría sociocultural; continuamos con la conceptualización de literacidad; enseguida, analizamos las entrevistas que realizamos a siete alumnos de la Licenciatura en Lengua Inglesa. Finalmente, analizamos si existe una clara relación entre los aspectos socioculturales y el nivel de literacidad.

Palabras clave: Lectura; escritura; sociocultural; lingüístico; literacidad.
Abstract. In this research, it is considered as a main issue that many newly enrolled students in the Language Faculty of the University of Veracruz present low levels of literacy compared to others who are proficient in it. This paper does not consider as an answer to these questions the fact that students are intellectually incapable, or without interest. This hypothesis is different. There are several differences in literacy levels between students because they are affected by sociocultural and linguistic aspects, which have a lot influence in the competent training or not of readers and writers. This paper is structured as follows: first, it defines and describes the sociocultural theory, and then, the conceptualization of literacy; next, the interviews conducted with 7 students of the BA in English Language are analyzed. Finally, it examines whether there is a clear relation between sociocultural aspects and literacy level.

Keywords: Reading; writing; sociocultural; linguistic; literacy.

\footnotetext{
${ }^{\text {I }}$ Para citar este artículo: Escarpeta Sánchez, José Ángel (20I9). La influencia de los aspectos socioculturales y lingüísticos en los niveles de literacidad: el caso de alumnos de la Facultad de Idiomas, Universidad Veracruzana. Alabe 19. [www.revistaalabe.com] DOI: IO.I5645/Alabe20I9.19.9
} 


\section{Introducción}

Una de las problemáticas más fuertes y cotidianas en la vida de los estudiantes de México es el de la lectura y la escritura. Por lo general, enfrentan escollos porque se les dificulta comprender un texto; lo mismo sucede cuando tienen que escribir un resumen, una reseña o un ensayo. Carlino (2005) y Parodi (2005), académicos prestigiosos, dedicados no sólo a impartir cátedra, sino también a investigar sobre lectura y escritura, son autores de libros que analizan el proceso lector y escritural, pero además hacen propuestas significativas para enfrentar ambos procesos. Uno de los libros de Carlino Escribir, leer y aprender en la universidad. Una introducción a la alfabetización académica, inicia con las siguientes preguntas retóricas “¿Por qué los estudiantes no participan en clase? ¿Por qué leen tan poco la bibliografía? ¿Por qué al escribir muestran haber comprendido mal las consignas?” (2005: 9). Mas Carlino no se queda sólo en la enunciación del problema, lo analiza y hace propuestas prácticas.

Otro libro imprescindible es el de Parodi titulado Comprensión de textos escritos. La teoría de la comunicabilidad; este autor también analiza los problemas que enfrentan los estudiantes con respecto a la lectura y la escritura. En una parte de su texto dice que a pesar de que se hacen constantes reformas educativas para soslayar dicho problema: "la mayoría de los sujetos de diversas edades, niveles educacionales y otras tantas variables que han sido objeto de investigación revela serias deficiencias en la comprensión de, incluso, breves textos instruccionales”. (2005: I2). Parodi, como Carlino, plantea a lo largo de su libro discusiones teóricas y prácticas para que los maestros encaren esta problemática.

En este trabajo ${ }^{2}$ planteamos como problema principal el que muchos alumnos de recién ingreso a la Facultad de Idiomas, Universidad Veracruzana, han presentado niveles bajos en literacidad, en comparación con otros que son competentes en estas actividades. ¿Qué es lo que hace que se dé esta diferencia? Si partimos de que en bachillerato existen perfiles de egreso homogéneos, ¿por qué existen esos contrastes tan polarizados?

Además de dos décadas impartiendo clases de lectura y redacción en la mencionada universidad, donde nos hemos encontrado con dicha problemática, partimos de dos investigaciones que consideramos fundamentales. La primera es la que aborda el tema de la deserción y reprobación en alumnos que recién ingresan a la universidad: Habilidades lingüisticas de los estudiantes de primer ingreso a las instituciones de educación superior del área metropolitana de la ciudad de México (González, 20I4), se trata de una investigación amplia y profunda acerca de los niveles en habilidades lingüísticas que traen los alumnos al entrar a educación superior.

La segunda es la que realizaron tres profesores de la Licenciatura en Lengua Inglesa a alumnos de esta carrera acerca de la deserción y la reprobación, en ella señalan:

\footnotetext{
${ }^{2}$ El presente artículo es parte de mi tesis de doctorado La influencia de los aspectos socioculturales y lingüisticos en los niveles de literacidad: el caso de los alumnos de la Facultad de Idiomas, Universidad Veracruzana; dicho posgrado es Estudios del lenguaje y lingüística aplicada, Universidad Veracruzana.
} 
"De acuerdo con los datos obtenidos, puede afirmarse que hay un alto índice de reprobación en experiencias educativas de las áreas de inglés y español ubicados al inicio de la licenciatura, de manera particular en los dos primeros periodos”. (Busseniers, Hernández y Núñez, 2OI4: 23).

En el caso de español, la experiencia educativa a la que se refieren los autores es "Lectura y redacción a través del análisis del mundo contemporáneo"; desde el examen de diagnóstico que se les aplica al inicio del curso, puede verse que existen grandes diferencias entre los que son competentes en lectura y escritura, de acuerdo a los perfiles de egreso de bachillerato, y los que arrastran serias deficiencias. Esta problemática se ve reflejada durante el curso y en los resultados que obtienen al finalizarlo. ¿A qué se debe tal situación? Tomamos como punto de partida el supuesto de que pueden existir diversos factores, entre ellos los socioculturales, que afectan el aprendizaje y conllevan a tener un bajo nivel. Pero no sólo pueden influir de forma negativa, esos factores también pueden ayudar a tener un rango mayor. Intentamos mostrar que los niveles de literacidad -altos o bajos- que arrastran los alumnos que ingresan a la Facultad tienen que ver también con aspectos como la economía, la lengua, la cultura, la geografía e, incluso, la religión. Asimismo, nuestra pretensión es que este trabajo contribuya, de alguna manera, a considerar otras formas de acercamiento a la lectura y la escritura en todos los niveles de educación; esto es, que se consideren los diversos factores socioculturales y lingüísticos donde se fue formando el alumno.

Hemos estructurado este trabajo de la siguiente manera: iniciamos con la definición y explicación de qué es la teoría sociocultural, continuamos con la definición de literacidad, enseguida analizamos parte de las entrevistas que realizamos a siete alumnos de la Facultad de Idiomas, Licenciatura en Lengua Inglesa, UV, semestre febrero/julio 2017 .

\section{La lectura y escritura desde una perspectiva sociocultural}

Estudios profundos en diferentes países demuestran que los niveles bajos en comprensión lectora repercuten en la reprobación y deserción de los alumnos. Podemos citar como ejemplos las investigaciones de Londoño (2OI2) y González (2OI4).

No basta con crear programas de promoción de lectura, o dotar de libros a las escuelas, o forzar a los maestros para que éstos a su vez obliguen a los estudiantes a leer. Mucha razón tiene Daniel Pennac (2003: II) cuando habla de los derechos de los lectores; en primer lugar inicia su texto con la frase: "El verbo leer no soporta el imperativo". Por lo tanto, en ningún momento se debe obligar a leer a nadie; más adelante confirma por qué no acepta el imperativo: “¿Y si, en lugar de exigir la lectura, el profesor decidiera de repente compartir su propia lectura?" (p. 79). Pennac está en contra del dogma "Hay que leer"; lo ideal es que el docente antes de ordenarle al alumno que sea lector, primero debe serlo él. 
Cuando una persona lee, existen muchas razones para hacerlo, pero quizás también enfrente obstáculos: puede ser interesante el texto para el lector, sin embargo, no lo entiende; puede ser complejo y entonces buscar estrategias, mas a pesar de eso no lo comprende; puede ser que esté muy bien escrito, con un lenguaje sencillo, pero aun así el lector no logra profundizar en él. He aquí la problemática, leer y leer y no entender, o como tituló un libro suyo Juan Domingo Argüelles: Estás leyendo... ¿y no lees? (2OII). Argüelles sigue la misma propuesta de Pennac, si para alguien resulta tediosa la lectura, pues mejor evitarla. Leer debe llevar al lector al placer; sin embargo, quizás por influencia de la cultura judeo-cristiana, muchos creen que aquello que produzca complacencia por sí mismo es pecado. Entonces, leer por gusto, por disfrute, por gozo, en donde finalmente no haya un producto, será una lectura que nosotros llamamos onanista ${ }^{3}$.

Quienes piensan que la lectura debe darse de manera obligatoria seguramente no toman en cuenta que para ser buen lector no basta tan sólo con tener ganas, hay muchos factores que pueden influir para que se comprenda lo que se lee.

Uno de los factores que consideramos primordiales es el sociocultural. Es por eso que a continuación haremos una breve reseña de éste. La teoría sociocultural tiene como antecedente importante al psicólogo soviético Lev Semiónovich Vigotsky (I995); él estudió las funciones psíquicas superiores del ser humano: memoria, razonamiento, resolución de problemas. Estas funciones las vincula con los procesos socioculturales; de esta manera, Chaves (200I: 6o) explica la propuesta de Vigotsky: “(...) el desarrollo ontogénico de la psiquis del hombre está determinado por los procesos de apropiación de las formas histórico-sociales de la cultura; es decir, Vigotsky articula los procesos psicológicos y los socioculturales y nace una propuesta metodológica de investigación genética e histórica a la vez"; de tal manera para este autor, las funciones superiores del pensamiento son producto de la interacción cultural.

Louise M. Rosenblatt es otra pionera de la teoría sociocultural; Vigotsky expuso esta teoría a fines de los años veinte; Rosenblatt, en r938 con la publicación de su libro $L a$ literatura como exploración (2002). Los planteamientos de esta autora son, en términos generales, que el texto y el lector se complementan; ni el significado lo tiene únicamente el texto, ni tampoco quien lo lee. Rosenblatt llamó transaccional a su modelo de lectura. María Eugenia Dubois comenta en el Prólogo del libro citado que la obra de esta autora aporta una nueva manera de ubicar al lector frente al texto; además, su concepto de transacción permite una relación distinta entre alumno y profesor.

Transacción significa llegar a un acuerdo, a un convenio; y eso es precisamente lo que propone Rosenblatt; el autor de un texto expone sus ideas, el lector las comprende, finalmente, será éste el que haga una transacción con lo leído: "Estoy de acuerdo con esto pero no con lo otro"; "Tienes razón desde tu punto de vista pero no coincide con el

\footnotetext{
3 Denominamos lectura onanista a aquélla que se realiza únicamente por hedonismo, por placer, sin que el lector tenga la obligación de presentar un producto específico (reporte de lectura, comentario, escribir una reseña o un ensayo). Aunque la Real Academia define el término onanismo como masturbación, nosotros lo tomamos con el significado antes mencionado, ya que leer debe ser un acto gozoso en solitario.
} 
mío"; "Únicamente comparto tus ideas pero no las acepto"; expresiones que se escuchan cotidianamente al comentar un texto. Rosenblatt hace hincapié en que: "El lenguaje es desarrollado socialmente, pero es siempre compuesto por individuos con sus historias particulares". (2OO2: 52). La anterior afirmación de Rosenblatt nos permite justificar de manera más sólida la razón por la cual debemos investigar las historias de vida lectoras de algunos alumnos.

Además, esta autora habla de por lo menos dos tipos de lectura, aquélla que tiene un fin utilitario y la otra, la que sirve como placer o que nosotros hemos llamado onanista. Con respecto a la primera, a la que denomina eferente (del latín efferre, "llevar afuera"), afirma que se realiza cuando el lector se centra en leer detenidamente, subrayando, anotando al margen de la página las ideas que para él son importantes, y que le servirán para presentar un reporte de lectura o realizar una exposición. Es por esto que para ella es una lectura utilitaria. En términos académicos, será un reporte de lectura; o una técnica de estudio, según María Teresa Serafini (2002).

En cuanto a la segunda, se refiere a la lectura con fin estético; ésta es muy personal, casi íntima; nadie puede leer un poema -parafraseando a Rosenblatt- por nosotros y transmitirnos totalmente las sensaciones que le provocaron esas palabras poéticas. La autora afirma que cada uno debe vivir (disfrutar, sufrir, paladear) la experiencia de la lectura; de allí que manifieste que el papel del lector es activo, nunca pasivo.

Daniel Cassany también desarrolla la teoría sociocultural, principalmente en su libro Tras las líneas. Sobre la lectura contemporánea (2006). Él habla de tres concepciones de la lectura: lingüística, psicolingüística y sociocultural. En cuanto a la lingüística, señala que ésta afirma que el significado de un texto se encuentra en el escrito; por su parte la psicolingüística afirma que el significado se halla en la mente del lector; finalmente, de la sociocultural enumera, entre otras, las siguientes dos características:

I. Tanto el significado de las palabras como el conocimiento previo que aporta el lector tienen origen social.

2. El discurso no surge de la nada. Siempre hay alguien detrás (...). El discurso refleja sus puntos de vista, su visión del mundo. Comprender el discurso es comprender esta visión del mundo. (Cassany, 2006: 33).

Como puede apreciarse, los tres teóricos mencionados comparten la misma idea acerca de lo sociocultural en la lectura. Los tres hacen hincapié en que todos los lectores leen y comprenden lo escrito en relación con lo que los rodea y los ha rodeado, ya sea esto de tipo económico, cultural, lingüístico o religioso.

Por lo expuesto anteriormente, es claro que nuestra postura ante la lectura es sociocultural; esto es, nos resulta primordial analizar cómo leen los estudiantes, ver cuáles son sus aciertos y fallas como lectores, pero sin dejar de lado la parte sociocultural, ya que ella nos dirá mucho sobre la alfabetización que han tenido en su trayectoria como estudiantes. 


\section{Literacidad o el uso de la lectura y la escritura}

Con respecto a la literacidad, mucho se ha analizado, escrito y difundido sobre ella. Se ha definido de diversas maneras, dependiendo de la perspectiva que se le dé. Desde el enfoque sociocultural, a partir de los Nuevos Estudios de Literacidad, principalmente, se considera a la literacidad como una práctica social fundamental que rescata el contexto de uso de la lengua escrita y las relaciones sociales y de poder que se originan.

Virginia Zavala define la literacidad en términos de lo práctico: "La literacidad siempre implica una manera de usar la lectura y la escritura en el marco de un propósito social específico". (Zavala, 2009: 23); por su parte, Melanie Elizabeth Montes Silva y Guadalupe López Bonilla (20I7: I64), apoyándose en otros autores, conceptualizan de esta forma la literacidad:

[...] se entiende que la literacidad es un "conjunto de prácticas discursivas, es decir... formas de usar la lengua y otorgarle sentido tanto en el habla como en la escritura" (Gee, 2004: 24). Es una práctica aprendida por el ser humano para que le sea útil a sus propósitos e "implica una manera de usar la lectura y la escritura en el marco de un propósito social específico”. (Zavala, 2008: 7I) y, sobre todo, es "algo que la gente hace... es esencialmente social y se localiza en la interacción interpersonal” (Barton y Hamilton, 2004:Io9).

Si bien el término literacidad ha causado polémica porque proviene del inglés literacy, Cassany opta por él pues considera que es el más apropiado, el que realmente tiene el significado preciso, ya que afirma que conlleva mayor claridad, es neutro y tiene una correspondencia muy cercana con palabras de otros idiomas. Concluye su afirmación de esta manera: “Además, se puede usar en plural (literacidades) para dar idea de diversidad y en formas como bilateracidad (leer y escribir en dos idiomas) o multiliteracidad (en varios)". (2006: 42).

Cassany también comenta en el texto referido las discusiones que se han dado debido a que muchos teóricos prefieren utilizar otras denominaciones distintas a literacidad, como por ejemplo letrado, o en el caso de Ferreiro (I999) que opta por alfabetización o cultura escrita, aunque finalmente no esté totalmente de acuerdo con ninguna de las dos ${ }^{4}$.

\footnotetext{
4 “(...) en muchos casos traduzco literacy como "cultura escrita”, porque tiene sentido y sabemos de lo que estamos hablando; en otros contextos, literacy es alfabetización. Pero tampoco alfabetización es muy adecuado, porque resulta incómodo utilizar este término cuando tienes que hablar de 'alfabetización en un sistema no alfabético'. El término alfabetización está muy ligado al alfabeto. En este momento nadie se siente cómodo con los términos disponibles". Emilia Ferreiro. (I999: IO3). “La importancia de la reflexión teórica” en Cultura escrita y educación. Conversaciones con Emilia Ferreiro. México: Fondo de Cultura Económica.
} 
Para finalizar este apartado, debemos dejar claro que entendemos y manejamos en este trabajo el concepto de literacidad como el conjunto de acciones prácticas que lleva a cabo una persona alfabetizada (que sabe leer y escribir) en el espacio donde vive. Esto es, con el significado de una práctica social específica que realizan quienes están alfabetizados.

\section{Historias de vida lectoras}

Utilizamos el enfoque biográfico-narrativo para acercarnos a los alumnos y poder conocer sus historias de vida, ya que como dicen Yolanda Puyana y Juanita Barreto (I994: I87):

La historia de vida proporciona una lectura de lo social a través de la reconstrucción del lenguaje, en el cual se expresan los pensamientos, los deseos y el mismo inconsciente; constituye, por tanto, una herramienta invaluable para el conocimiento de los hechos sociales, para el análisis de los procesos de integración cultural y para el estudio de los sucesos presentes en la formación de identidades.

Debemos afirmar sin empacho que el uso del enfoque biográfico-narrativo nos permitió conocer aspectos de la vida estudiantil de los jóvenes que quizás con otro enfoque no lo hubiéramos logrado. Algunos de los entrevistados llegaron, incluso, a emocionarse con los recuerdos de sus primeros años de escuela.

Consideramos importante subrayar que en este trabajo no desarrollamos todo el marco metodológico que sí construimos en nuestra tesis de doctorado. Realizamos entrevistas a siete alumnos de la licenciatura en Lengua Inglesa, Facultad de Idiomas. En ellas, tratamos de indagar cuál ha sido la historia de lectura de cada uno. Estimamos que los alumnos entrevistados son más que participantes, aportan sus conocimientos, sus experiencias, por lo que para nosotros son colaboradores. Por motivos de no ser repetitivos los nombramos a lo largo del texto también como alumnos, estudiantes, entrevistados o jóvenes, pero siempre con el significado de colaboradores.

Los siete alumnos de Lengua Inglesa, que accedieron a colaborar en nuestra investigación son 4 mujeres y 3 hombres; en abril-mayo de 20I7, tiempo en que los entrevistamos, estaban inscritos en la experiencia educativa "Gramática comunicativa del español".

Las respuestas de los alumnos (grabadas con previo permiso de cada uno de ellos), las clasificamos en los siguientes aspectos: geográfico, económico, social, cultural, lingüístico y religioso (más adelante explicaremos qué entendemos de cada uno de ellos). Con respecto al análisis de las historias de vida, sólo incluimos fragmentos de la conversación con una entrevistada a la que llamaremos Yesenia.

Los aspectos socioculturales y sus definiciones son los siguientes: 
a). Geográfico: se refiere a la parte geográfica (ciudad o pueblo) en donde inició y cursó el alumno entrevistado sus estudios, principalmente los de Educación Básica. El objetivo de conocer la ubicación geográfica se debe a que nos interesa saber el nivel cultural de dicho lugar o qué tan lejos o cerca está de un centro que tenga un nivel alto, por ejemplo, Xalapa, a la que se le considera la Atenas Veracruzana u otra ciudad del estado veracruzano.

b). Económico: nos referimos al "Conjunto de bienes y actividades que integran la riqueza de una colectividad o un individuo". Diccionario de la Real Academia Española (DRAE. 20I4). Cabe aclarar que en el caso de los entrevistados, no precisamente se trata de indagar qué riquezas poseen sus padres, sino el nivel económico en que se encuentran, y si éste influyó para que apoyaran o no a sus hijos en la continuación de sus estudios.

c). Social: este aspecto lo entendemos como el "Conjunto de personas, pueblos o naciones que conviven bajo normas comunes". (DRAE. 2OI4). E intentamos rastrear si dentro de estas normas se concibe el estudiar como algo primordial o sólo se considera como una actividad de menor importancia.

d). Cultural: es un término bastante polémico y con muchos significados. El DRAE (2OI4) lo define así: "Conjunto de modos de vida y costumbres, conocimientos y grado de desarrollo artístico, científico, industrial, en una época, en un grupo social”. En este aspecto nos importa averiguar cómo las costumbres, las formas de vivir, los tipos de trabajos que existen en la ciudad, pueblo, comunidad, colonia, inciden en la manera de concebir la literacidad.

e). Lingüístico: nos referimos a la forma de expresarse oralmente (organización de ideas, coherencia, cohesión, muletillas, uso incorrecto de palabras de acuerdo a la normativa); también si en los lugares de origen de los entrevistados se hablaba otra lengua además del español en la época de infancia de los entrevistados. La razón: en caso de que así fuera, analizar si ésta o éstas influyeron, y cómo, en el español del hablante.

f). Religioso: "Conjunto de creencias o dogmas acerca de la divinidad, de sentimientos de veneración y temor hacia ella, de normas morales para la conducta individual y social de prácticas rituales, principalmente la oración y el sacrificio para darle culto" (DRAE. 20I4). En este aspecto, la pretensión no es saber si creen o no en un dios, lo que se busca es indagar si desde niños los acercaban a la lectura, sin importar que fueran textos religiosos. Asimismo, averiguar cómo leían, si les enseñaban estrategias de lectura, por ejemplo. 


\section{Análisis de las historias de vida lectoras}

Una vez transcritas las conversaciones de los colaboradores, examinamos por aspecto las respuestas ${ }^{5}$ y analizamos qué posible relación podían tener con los niveles de literacidad que los alumnos presentan actualmente. Los fragmentos que citamos corresponden, como se señaló arriba, a la colaboradora Yesenia.

En cuanto al aspecto geográfico: tres de los entrevistados son originarios de Xalapa y cuatro pertenecen a comunidades cercanas a la capital veracruzana. Sobre este aspecto, Yesenia afirmó:

\section{"[...] yo soy de allá, de Perote, Veracruz; [con el tiempo] me mudé más al centro} de Perote, más al centro".

\section{".... en Victoria es mucho así como de pueblito... muy, muy de pueblito, cuando} llegué a Perote me quedé así como se visten de otra manera, este, hablan de otra manera, se llevan de otra manera, y... cómo se llama, [...] se pueden divertir [...]". "[Allá en Victoria] Era una escuela donde el maestro... cómo se llama... daba todas las materias. Casi no había muchos recursos, así... al igual que estaba el salón... el pizarrón estaba roto... y cómo se llama, no había muchos recursos, estaba... como es un pueblito, por lo mismo, [... ] estaba muy pobre en recursos".

En el aspecto económico: cinco se encuentran en un nivel medio bajo; sólo dos en el nivel medio. Igualmente, cinco estudiaron en escuelas públicas y dos en privadas. Cinco han tenido problemas para seguir estudiando debido a la situación económica precaria de sus padres y familiares. Los padres de esos mismos cinco alumnos mencionados antes no tienen trabajos bien remunerados, por ejemplo, se desempeñan como traileros ${ }^{6} \mathrm{o}$ dueños de talleres mecánicos. Los otros dos coinciden en que los negocios de los padres reciben buenas ganancias. El nivel de estudio y empleos de los padres varían y sí existen grandes diferencias. Las mamás: cuatro sólo estudiaron la secundaria y son amas de casa, dos tienen carrera universitaria y trabajan en el magisterio, una más estudió enfermería y se desempeña en un hospital. Los papás: dos estudiaron la secundaria y son mecánicos, uno cursó bachillerato y se dedica a la panadería, otro actualmente estudia para abogado y tiene un empleo en gobierno, otro más estudió sólo la primaria y es trailero, el otro padre estudió secundaria y tiene un negocio propio, finalmente, otro padre es ingeniero, pero se dedica a atender su negocio que consiste en una flotilla de taxis. Yesenia comentó que

\footnotetext{
5 Para el análisis de la información, nos apoyamos en el programa Atlas.ti, el cual permite codificar y clasificar los testimonios de los colaboradores por apartados. "El programa ATLAS/ti es una herramienta diseñada para ayudar al analista en la interpretación de los datos textuales". (Penalva et al., 2OI5: I27). Este programa nos permitió clasificar los seis aspectos para luego editarlos y darle una forma de narración que nos permitiera analizarlos e interpretarlos. Fue una actividad de recortar, pegar, zurcir, e ir dándole coherencia al texto transcripto con el uso de palabras o frases.

6 Trailero, en el contexto mexicano, significa el que maneja un tráiler.
} 
debido a la mala situación económica de sus padres estuvo a punto de dejar los estudios:

“[Hace un tiempo], dos meses, que sí llegué a [pensar] que en realidad sí me voy a tener que salir de la escuela porque... cómo se llama... ya no nos daba porque no solamente soy yo, también tengo dos hermanos. Llegué a pensar eso... voy a trabajar y todo eso; dejo la escuela y... cómo se llama... toda la semana trabajo y allá... en Perote también hay universidad tecnológica y pues me dije, los fines de semana estudió allá... pero cómo se llama... pero pues hubo un poco de ayuda por parte de un familiar y ya pues ahorita sigo; pero sí llegué a pensar en dejar el estudio por motivos económicos”.

En el aspecto social: la mayoría de padres, familiares y personas de la comunidad veían y ven al estudio en general como una posibilidad de cambio de estatus social; esto es, quien más estudie tendrá mayores posibilidades de tener dinero y vivir mejor. Sin embargo, a esta postura (tres alumnos originarios de Xalapa así lo expresaron) se opone la otra, donde los adultos expresaron (originarios de comunidades fuera de Xalapa) que era mejor ponerse a trabajar desde joven para hacer dinero, la experiencia de estas personas es que ellos no necesitaron estudiar para reunir un capital. Cabe mencionar que en algunos casos estas dos posiciones coincidían de esta manera: si los niños y jóvenes van a estudiar que sea una carrera productiva, esto es, en donde puedan hacer dinero. Así expresa Yesenia la forma en que se concebía en su pueblo el estudio:

"Pues allá [en el pueblo de Victoria], cómo se llama... si tú ya sabías leer y escribir ya sabías; ya te tenías que ir a trabajar. Nada más lo básico era que supieras leer y escribir, o por lo menos escribir, porque ... cómo se llama, muchos niños de hecho ya nada más con que sepan hacer cuentas y leer y escribir ya se podían ir a trabajar".

"[Recuerdo que en el pueblo] Era muy difícil que un padre te inculcara la lectura. Creo que actualmente no... yo que he regresado allá a Victoria, cómo se llama... no... todavía sigue ese problema de que no quieren... todavía sigue ese tipo de que no quieren que los niños aprendan o salgan más allá de lo que deberían de salir. No leen, no dan optimismo o ¿cómo se podría decir? No les dan un empujón para que salgan adelante, sino quédate, trabaja y ya".

En el aspecto cultural: existen coincidencias en cuanto a que la lectura sólo se veía desde la perspectiva utilitaria: aprender a leer y a escribir sirve para que no engañen a las personas, para que se sepan defender, para que puedan trabajar o poner un negocio. La colaboradora Yesenia evoca este punto de vista: 
"Pues allá [en el pueblo de Victoria], cómo se llama... si tú ya sabías leer y escribir ya sabías; ya te tenías que ir a trabajar. Nada más lo básico era que supieras leer y escribir, o por lo menos escribir, porque ... cómo se llama, muchos niños de hecho ya nada más con que sepan hacer cuentas y leer y escribir ya se podían ir a trabajar".

En algunos hogares, sobre todo en las comunidades, no existían libros, y si los había, no los utilizaban. La mayoría de las escuelas públicas carecían de bibliotecas escolares, ya no se diga de un espacio bibliotecario público; y en la comunidad donde el alumno reconoció que existía, tuvieron que cerrarla porque la gente no acudía a ella. La diferencia es marcada con los estudiantes de la capital, en las casas sí hay libros, y sí los usan, sobre todo cuando los padres o hermanos mayores están estudiando o son profesionistas.

Con respecto a la lectura de cuentos en su infancia, sólo cuatro jóvenes recuerdan que sus mamás les leían cuentos; los otros tres no se acuerdan. También sobresale una situación, cinco colaboradores afirman haber aprendido a leer en la escuela, uno en su casa con su mamá, y otro que no recuerda. Seis alumnos expresaron que en sus casas no les inculcaron el hábito de la lectura; uno llegó a decir que su papá lo obligaba a leer, por lo que se convirtió en un renegado de la lectura. Esta poca motivación hacia la lectura también la vivieron los jóvenes en su transitar desde el jardín de niños hasta la preparatoria. Sólo los dos alumnos que estudiaron en escuelas privadas recuerdan que sus maestros (y no todos) de los diferentes niveles les inculcaban el hábito de la lectura. La mayoría de los entrevistados evoca únicamente a un maestro de la secundaria o de la preparatoria que los haya invitado a leer; otros, hasta que llegaron a la facultad se encontraron con el argumento de que ser lector era básico para continuar en ésta. Sobresale la mención de una entrevistada que afirma que ella se ha hecho lectora gracias a una amiga que conoció al ingresar a la carrera universitaria.

En los casos en que los jóvenes no se han hecho lectores, existen varias constantes: primero, culpan a los padres y al sistema educativo nacional por no haber preparado óptimamente a maestros en español, o haber ingresado a la docencia a personas que, aun siendo especialistas en español, no les agradara leer; segundo, el no ser lectores competentes les impide saber escribir correctamente, situación que los ha llevado a reprobar experiencias educativas de español en la carrera de Idiomas, Lengua Inglesa; tercero, la falta de una cultura letrada por parte de las autoridades educativas que incluso teniendo bibliotecas en las escuelas, restringen los préstamos y atesoran los libros como si guardarlos fuera la razón de las bibliotecas y, cuarto, la carencia de una conciencia sensible de los gobernantes a las necesidades de la población más necesitada económicamente que debe elegir entre comer o gastar en los estudios de los hijos.

En el aspecto lingüístico: los informantes reconocieron sólo hablar español, en dos casos también inglés. Aquí cabe señalar que los alumnos que han vivido en Xalapa desde pequeños tienen mayor fluidez verbal en comparación con los que son originarios 
de comunidades alejadas a Xalapa. Podemos citar como ejemplo dos casos, una alumna respondía de manera tan breve que en muchas ocasiones nosotros terminábamos hablando más que ella; el otro caso es el de una joven que todo el tiempo utilizó la misma muletilla, e incluso llegó a decir "haiga" en lugar de haya. La entrevistada aludida es Yesenia:

"[...] así me prestaba bonitos libros, libros que me gustaban a mí, del género romántico que me gustaba a mí demasiado, y ahí fue cuando se me inculcó más la lectura y ya en la prepa jue ahídonde fue más lectura a fuerza (risa de la entrevistada) a fuerza porque pues no me daban lectura que me gustara pues que ya era de la escuela y todo".

"Mmm, en mi casa no se hablaba [el náhuatl]. Lo empezó a estudiar mi amá, principalmente".

"Eeeh, se podría decir que más o menos, depende de las palabras que haiga. Luego sí hay palabras que son difíciles de explicar o hay, cómo se llama... no sé a veces sí se me dificulta, de hecho, pero hay veces que cuando ya le empiezas ya le entiendes y ya puedo".

En el aspecto religioso: seis alumnos no tuvieron acceso en su infancia a textos religiosos; una alumna reconoció que el ser lectora de textos bíblicos desde pequeña sí le permitió convertirse en lectora asidua. Yesenia fue una de las entrevistadas que de niña nunca leyó textos religiosos:

Desde chiquilla a mí me inculcaron lo que era la religión católica normal; no me inculcaron mucho que tuviera que leer la Biblia; no fue hasta como en la prepa que me dijeron que ya la leyera para que aprendiera (...)"

\section{Conclusiones}

El análisis de las entrevistas de los informantes nos ha permitido llegar a las siguientes conclusiones:

En primer lugar, los jóvenes no originarios de la capital veracruzana presentan problemas en su discurso verbal en comparación con los de Xalapa; el vocabulario de los primeros es más limitado; el de los segundos, más organizado.

En segundo lugar, los alumnos que han tenido problemas económicos, de alguna manera, se han visto afectados en sus estudios. Incluso, la falta de dinero ha ocasionado que no puedan comprar libros que les piden en la universidad. La ideología predominante de que lo más importante es el dinero se refleja en el abandono de la escuela por ir en la búsqueda de actividades que remuneren capital. Lo anterior influye poderosamente en la cultura que se ha creado, leer no reditúa dinero, entonces no es importante ser lector. Encontramos el caso de una alumna que contó que sus padres, maestros los dos, se 
preocupaban porque aprendiera matemáticas, según ellos, porque le sería muy útil en su vida diaria; que leyera, afirma, nunca le dijeron. Sólo en los casos en los que la lectura y la escritura permitan acceder a la riqueza se convierte en primordial.

En tercer lugar, si la lectura y la escritura no se enseñan desde la casa, será difícil formar un buen lector; lo mismo ocurre en las escuelas, en las que se hace énfasis en el conocimiento científico, pasando a segundo término la enseñanza de las humanidades, aquí se germinan futuros ciudadanos que verán a la literatura y el arte en general como actividades no productivas, no objetivas, no importantes.

Finalmente, esta investigación nos ha llevado a confirmar que los factores socioculturales influyen poderosamente en los niveles de literacidad de los estudiantes. Quien llega a una universidad sin una formación lectora y escritural, tendrá serios problemas en sus posteriores estudios. Confirmamos tal aseveración con el caso de los alumnos colaboradores que recordaron no haber tenido contacto con libros desde pequeños, ni en la casa ni en la escuela; los que evocaron una situación económica difícil que les ha impedido comprar libros. Pero de esto no son culpables en su totalidad los alumnos. ¿Cómo puede formarse un buen lector si en su comunidad la lectura carece de importancia?, ¿cómo lo será si saliendo de la escuela debe ir a trabajar y regresar muy tarde y sin tiempo para hacer la tarea?, ¿cómo logrará comprender lo que lee si no tiene acceso a libros que complementen lo que el profesor les explicó en clase?

Para que los niños y jóvenes sean lectores en toda la extensión de la palabra no basta con regalar libros, crear círculos de lectura e invitar a promotores de lectura a las escuelas; hay más cosas que hacer. Acciones primordiales como elevar la calidad de vida de la niñez y juventud; evitar la pobreza extrema en donde no se tenga que elegir entre llevarse un bocado a la boca o comprar un libro; actualizar a los maestros y comprometerlos a que fomenten la lectura y la escritura en todos los niveles de enseñanza.

En México, existen periódicos más caros que lo que cuesta un kilo de tortillas;; nos preguntamos ¿país de lectores?, ¿cómo?, si primero hay que pensar en lo básico: alimentación, medicamentos, ropa. ¿De qué manera se van a formar lectores críticos si el acceso a la prensa es caro, y los medios televisivos presentan una realidad fabricada de acuerdo a los intereses de una clase privilegiada que finalmente le conviene conservar un país de no lectores?

Un joven podrá ser muy inteligente, muy capaz, pero si las condiciones socioculturales no le han permitido formarse más allá de su comunidad, cómo podrá ser un lector competente. La lectura implica una red de intertextualidades, si se ha vivido en un mundo donde no se ha tenido acceso a conocimientos generales, comprender un texto resulta difícil. Por eso concluimos, ser buen lector y escritor no sólo depende de la inteligencia, sino también de los aspectos socioculturales que desde niño rodean a la persona.

\footnotetext{
7 En México, el país, la tortilla es el alimento primordial (se cocina de diversas formas, se consume de muchas maneras). En los inicios de 2018 el precio fluctúa entre \$I2 a \$I5. Un periódico de circulación nacional tiene un costo entre $\$_{15}$ a $\$ 25$.
} 
Quizás haya quien alegue que mejorar las condiciones socioculturales no es tarea ni puede hacerlo un docente; es cierto, pero no se trata de qué sí puedo hacer y qué no. Si existe un proyecto nacional para hacer un México lector, entonces hay que luchar para que los Planes y Programas de estudio contemplen que los alumnos no son seres aislados de la realidad social y cultural del país donde viven. A la par de un nuevo sistema escolar, debe existir un programa nacional que apoye a todos los estudiantes, no sólo con becas para los de mejores calificaciones (la contradicción, cómo va a rendir un niño desnutrido y que apenas come con otro que desayuna muy bien, por ejemplo). Si las autoridades educativas exigen evaluar a todos los alumnos de manera homogénea, sin interesarles las enormes diferencias socioculturales, entonces que primero busquen alternativas para darles una mejor calidad de vida a los más desprotegidos.

Por último, los que trabajamos en el área de lenguaje, de gramática y de literatura debemos tener el compromiso de rastrear estrategias para tratar de nivelar a nuestros alumnos que arrastran una formación deficiente en lectura y escritura. 


\section{Referencias bibliográficas}

-Argüelles, J. D. (20II). Estás leyendo... ¿y no entiendes? Un libro contra la obligación de leer. México: Ediciones B.

- Carlino, P. (2005). Escribir, leery aprender en la universidad. México: FCE.

- Cassany, D. (2006). Tras las líneas. Sobre la lectura contemporánea. Barcelona: Anagrama.

- Ferreiro, E. (I999). "La importancia de la reflexión teórica" en Cultura escrita y educación. Conversaciones con Emilia Ferreiro. México: Fondo de Cultura Económica.

- González, R, R. O. (Coordinadora). (2014). Habilidades lingüísticas de los estudiantes de primer ingreso a las instituciones de educación superior del área metropolitana de la cüdad de México. México: ANUIES.

- Montes S, M E y López B, G. (20I7). Literacidad y alfabetización: enfoques teóricos y propuestas pedagógicas. Perfiles Educativos XXXIX (I55). México: UNAM. I62-I78.

- Pennac, D. (2003). Como una novela. Barcelona: Anagrama.

- Rosenblatt, L. M. (2002). La literatura como exploración. México: Fondo de Cultura Económica.

- Serafini, M A. (2002). Cómo se estudia. La organización del trabajo intelectual. México: PAIDÓS.

- Parodi S, G. (2005). Comprensión de textos escritos. La teoría de la Comunicabilidad.Buenos Aires: Eudeba.

- Puyana, Y. y Barreto J. (i994). La historia de vida: recurso en la investigación cualitativa. Maguaré. Núm. Io. Bogotá: Universidad Nacional de Colombia.

-Vigotsky, L. (1995). Pensamiento y lenguaje. Barcelona: Paidós.

- Zavala, V. (2009). La literacidad o lo que la gente hace con la lectura y la escritura. Para ser letrados. Barcelona: Paidós. 


\section{Referencias electrónicas}

- Busseniers, E. P., Hernández, C. R. y Núñez, M. P. “La deserción de los estudiantes de Lengua Inglesa desde la perspectiva de la institución” en Hernández, A. M. M y Narváez, T. O. M (Coordinadores). La deserción escolar en la facultad de Idiomas: perspectivas de la comunidad educativa. (20I4). (pp. II-35). Recuperado de

https://www.uv.mx/bdh/files/2OI4/O4/Libro_desercion_escolar.pdf

- Chaves, A. L. (2OOI). "Implicaciones educativas de la teoría sociocultural de Vigotsky" en Educación. Recuperado de http://www.redalyc.org/articulo.oa

- Londoño, V, D. A. (2012). Análisis sociolingüístico de los niveles de literacidad en jóvenes de la Institución de Envigado. Tesis doctoral. Universidad de Envigado: Envigado. Recuperado de http://biblioteca.clacso.edu.ar/Colombia/alianza-cinde-umz/

- RAE (2OI4). Diccionario de la Lengua Española. (Vigésima Segunda Edición). Recuperado de http://www.rae.es/drae/

-Zavala, V. (2008). "La literacidad, o lo que la gente 'hace' con la lectura y la escritura" en Textos de didáctica de la lengua y la literatura. (47), 7I-79. Recuperado de https://lecturayescrituraunrn.files.wordpress.com/20I6/o2/zavala-la-literacidad-o-lo-que-hace-lagente-con-las-palabras.pdf 